\title{
IT TAKES A VILLAGE: IGNITING THE SCIENTIST IN LOWER TRACK STUDENTS THROUGH PARTNERSHIPS
}

\author{
Sen Kee Peter Seow, Chew Lee Teo, Chin Fen Ho, Kei Xian Tan, \\ Frederick Toralballa Talaue, \& Wei Loong David Hung \\ Office of Education Research, National Institute of Education (Singapore)
}

\begin{abstract}
The paper presents a study on a partnership between schools, a community welfare organization, Science Centre and the National Institute of Education to design, study and implement new approaches of learning for lower track students. Singapore as an inclusive society has sought to address the diverse educational needs of children in the country. This partnership seeks to ignite students' interest in learning Science and address the affective needs in learning, which includes developing students' confidence, competence and social skills. Leveraging on the diverse expertise and experiences, the partners designed tinkering activities to anchor students' learning experiences in exploring, testing and constructing Science ideas. The activities are designed and enacted with linkages to the existing Science curriculum. However, setting a partnership with stakeholders from different backgrounds and domains is challenging. We will describe the journey of setting up the partnership, developing shared goals, building capacity and knowledge, and designing for learning. Also, we will share students' learning and affective outcomes because of the partnership and participation in the designed tinkering activities. Our goal is to highlight how meaningful partnerships can be formed to better understand and meet lower track students learning and affective needs through collective social responsibility according to the familiar proverb "It takes a village to raise a child".
\end{abstract}

Keywords: Partnerships, learning, science, lower track students.

\section{Introduction}

In Singapore, after the Primary School Grade 6 national examinations, students at the age of 13 years old are tracked into various streams in Secondary schools based on their academic performance results. Students who performed well are tracked into the Express stream where they will take the GCE "O" levels examinations at the end of their fourth year, at the age of 16. For students who did not qualify for the Express stream, they are allocated to the Normal stream, which is deemed a lower track. Rather than attributing poor academic performance results to natural abilities, we postulate that these lower track students have diverse needs that require attention other than academic assistance. Therefore, we propose a partnership between schools, Science Centre, Student Community Services and an education research institute to design and implement new approach for Normal stream students. This Tinkering approach, which combines elements of fun and learning in Science, could potentially meet the social, affective and academic learning needs of lower track students.

\section{Design}

Using Design-Based-Implementation Research (DBIR) approach, schools and external agencies, formed partnership with the National Institute of Education (NIE) research team to design, plan and execute learning programmes to meet the diverse needs of lower track students. The ecology in this partnership is brought together by a shared goal to improve Normal stream students' learning and well-being through Tinkering approach in Science curriculum. With the iterative design processes put in place through common platforms such as meetings and workshops, partners get to share different perspectives on students, learn and unlearn new things about Tinkering approach and teaching ideas, as well as experimenting, creating and executing new Tinkering lessons in schools. In which, these learning outcomes of students will affect and inform the partnership outcomes, that builds a feedback mechanism within this interaction system. We hope that such mechanism can be an effective model of partnership and learning that is benefitting. 


\subsection{Lower track students}

Lower track students in Singapore are divided into Normal (Academic), NA, and Normal (Technical), NT, stream students, where the former will sit for GCE " $N$ " levels examination and the latter one, for GCE "NT" levels examination. Typically, the percentage of NA and NT comprises about $25 \%$ and $12 \%$ of students entering Secondary 1 respectively. Throughout the Secondary school education, the system hardly allows the flexibility of transferring to a better stream for better future paths, should the lower track child exhibits some level of potential to do well. In other words, their future paths are structured in a fixed way that they sit for different national examinations where the subject content has been reduced and adjusted to a certain extent, which is different from Express stream students. However in recent years, there is an increasing effort to widen opportunities for Normal stream students, especially for NA students who do well and show promising potential in a specific subject. Instead of shifting to a better stream, they remain in the original track but are offered an opportunity to study only that subject at a higher difficulty level. For example, a student does well for Science at the "N" level may be offered to do "O" level Science subject under the Subject-based Banding scheme in this flexible system structure.

Usually, school teachers will teach both "O" and "N" level subjects to students in the same level since the content and syllabus requirement are almost similar. But they may have neglected other differences these two categories of students have, possibly diverse needs other than academic abilities. Due to this negligence, the teaching approaches remains almost the same without taking into consideration the different learning needs of NA students. Prior studies (Tan, Wang, Ee, Koh \& Liu, 2009; McInerny, Liem, Ortiga \& Qi, 2008) on NA students found that they have stronger feelings of closeness to a social group and working with others rather than alone. They have a tendency towards learning for rewards which demonstrates their competence to produce the desired outcome towards achievements. Without the awareness of such diverse needs, this have resulted in lower track students who learn by memorizing instead of engaging in critical thinking. This mode of learning is reinforced by the way subject matter is taught to the lower track students. Learning materials presented emphasised on rote learning instead of challenging ways that foster critical thinking and problem solving skills (Wang, Teng \& Tam, 2014). Such approach to teaching Normal stream students could be due to teachers' perception that lower progress students are only capable of learning less complex content and skills (Kramer-Dahl \& Kwek, 2011). Kang's report (2005) on Normal Stream students' perception about thier teachers' expectation of them, concur that teachers do not expect them to master the depth of content materials compared to their express stream peers. Teachers define NA students by their weakness rather than their strength through a deficit perspective or thinking (Groski, 2008).

Typically, instructional approaches in the classroom also run counter to how lower track students' tendency to learn socially. Students often lack the opportunity to present their ideas and thoughts to their peers (Kaur \& Ghani, 2012) as teachers tend to have students work individually, apprehensive that the students would go off task in groups. Besides that, NA students' self-concept affect their learning in the subjects as well. Tang and her colleagues found that NA students' self-view in Science Learning and their views of the nature of Science were the strongest predictor of their Science inference competencies. (Tang, Goh, Aye \& Yeo, 2018). Their findings showed that NA students lacked confidence in their abilities in learning science. Additionally, they may have limited knowledge of what Scientists do and how Scientists go about experimenting and discovering new knowledge, in which this part of Scientific Endeavour is essential to attitudes in learning Science. Thus, this shows NA students' lack of understanding of what is involved in doing Science. As such, we proposed that NA students should be engaged in doing Science through complex problem solving that would develop their higher order thinking skills, a learning experience afforded by Tinkering approach. This will then give them another opportunity to prove themselves and enhance their self-concept that would lead to better academic outcomes.

\subsection{Partnerships}

Seeing the diverse needs of NA students in learning, this partnership between schools, the Science Centre (SC), Student Community Services (SCS) and the National Institute of Education (NIE) aims to design and develop learning programmes that help to promote and sustain their interests in Science. Traditionally, entities like the Science Centre and Student Care community are seen as service providers of after-school educational programmes for students, engaged by schools for short-term purposes. Schools periodically send students to visit the Science Centre where they can interact with interesting exhibits or attend hands-on workshops through experiential learning experiences anchored around science phenomena. As for Student Care community, they run student care centres where they provide after-school care for students through mentoring programmes or counselling services that would meet students' affective needs. In Singapore, an increasing number of such community welfare organisations provides welfare services to families, particularly to those who are in the lower income, who lack resources on mentoring and attending to their child. However, the programmes in the Science 
Centre and Student Care Services often run in isolation from the school curriculum and enrichment activities. They are perceived as meaningful "add-ons" to the numerous school activities that students are required to participate. In fact, some impactful learning episodes from these programmes are not effectively leveraged on by schools to complement the schools' mission and vision to the holistic development of students in general, an aspect especially important to NA students. We see this gap in the school-vendor relationship to be a great potential for the development of a meaningful and effective partnership in positively affecting NA students learning.

This project was initiated by a research team from NIE with a grant from the Singapore Millennium Foundation to propose and study innovative approaches to learning in Schools. The research team reached out to several schools and community services, and Science Centre to form the partnership. The Science Centre was interested in the partnership at the onset, as they were keen in developing students' interest in Science through tinkering approach, which is a fun and creative way of learning Science. Meanwhile, two public schools and one community services organisation also expressed interest in forming this unique partnership. Both schools see this project as an avenue to level up NA students' learning outcomes in Science education as well as improving their emotional well-being, while Student Care centre was more interested in the social emotional aspect of NA students through mentoring. Therefore, with the Science Centre providing expertise in tinkering approach, Student Care centre equipped with Positive Youth Development (PYD) knowledge and school teachers who are knowledgeable in Science curriculum, these three partners embarked on a research adventure with the research team, attempting to address a challenging issue.

At the start of our project, we focused on the following criticial processes: 1) building capacities of partners; 2) designing for learning; and 3) understanding NA students. These processes were critical as we understood the need for all partners to undergo the same learning experience of students in tinkering and understand the process of learning, hence empathize with the learners. Therefore, tinkering workshops are organised for partners to experience constructing classic tinkering activities such as Marble machines, creating circuits, and building scribbling bots using a diversity of familiar or recyclable materials. All partners shared their perspective and experience of tinkering and how it may benefit the NA students in Science learning or their well-being. These workshops presented opportunities to learn from the expertise of partners and build capacity of each partner. For example, the student care centre partners often shared about how to relate and converse with students to build confidence, and urged the rests to think about students' feelings that are sometimes played down in the process of designing for learning. Hence, their inputs represent students' voices that serve as reminders to partners about the important of understanding our learners in our design for learning processes.

As the project progresses after 16 months of partnership, those critical processes naturally evolved as many factors come into play, for instance the change in learning context for Tinkering from informal setting to a formal setting. Out of the four different tinkering activities designed and enacted thus far, first two activities were led by the Science Centre while the last two were led by teachers. In the first two activities, teachers observed how the Science Centre planned and executed Tinkering activity whereas in the latest two activities led by teachers, the Science Centre observed and supplied useful materials and information on possible ways to re-design tinkering activity to fit into the school curriculum and context without compromising much of the tinkering spirit, which often demands a great deal of resources and time. On the other hand, in order to enhance the well-being aspect in tinkering activities, the Student Care center partner recommended a structure that would better improve students' connections with their peers in learning, which would meet their needs to learn socially. Each partner contributed to the design by providing resources, ideas and the recommendations based on their expertise. Data and observations about the students collected in the tinkering activities were then shared to the partners by the research team. The perspectives of various partners as they interpret the data add to a more comprehensive understanding of NA students. These refined insights then enable the partners to better design learning experiences that lead to improved engagement of cognition and emotions in students' learning.

\subsection{Tinkering for science learning}

The Science Centre has been an advocate of tinkering as an approach to learning Science, inspired by the Tinkering Studio at the Exploratorium, a Science museum in San Francisco. Tinkering means 'thinking with your hands'. In short, while you are doing something, you figure out what is happening. It is an alternative approach to the familiar 'plan-then-do' method. The famous Noble Prize Physicist, Richard Feynman is an example of a Tinkerer. He played to discover Science. This tinkering experience is what we believe will benefit NA students.

The tinkering activities are characterised by their low floor and high ceiling design principles (Resnick \& Rosenbaum, 2013). By low floor, it means that the entry point to starting a tinkering activity is easy without much effort in thinking or planning. A variety of materials that are familiar or easily learn to use could trigger off the intuition in participants to start an activity. Also, there could be multiple starting points and pathways for the participants to pursue and complete the goal, or even complexify 
their products by having complex solutions, which marks the high ceiling. Tinkering activity afforded such learning experience for students to generate multiple ideas and solutions to a problem, as opposed to 'the best and probably the only solution to a problem' mindset, typically found in classroom teaching. Tinkering also provides an authentic Science learning experience that characterize the real world that is often complex and intriguing.

Tinkering focuses on the process undertaken by the participants to achieve the goal of the project and solve problems they may encounter during the task. They will iteratively test different ideas to solve the problem. The partners found that tinkering may be an approach that would interest students in learning science as it involves them in doing Science in more engaging ways than the traditional way of listening and thinking about Science. Constructing the marble machine and creating circuits covers aspects of school Science curriculum such as Energy, Friction, Materials, and Electricity. Students can learn and apply concepts such as a Kinetic and Potential Energy, Frictional force, or current flow as they are working on the tinkering projects. The iterative nature of tinkering can imbue a sense of perseverance and develop confidence as they overcome failed ideas and challenging moments. Working with others can meet NA students' need for affiliation while learning together. To them, collaborating with their friends is considered 'fun'; working with their partners create bonding opportunities that they treasure in the learning process, as shown in some of the students' excerpts from the recent surveys and interviews about Marble Machine activity with the 13-year olds (Table 1):

Table 1.

\begin{tabular}{|c|c|}
\hline $\begin{array}{l}\text { Student's } \\
\text { engagement }\end{array}$ & Students' excerpts \\
\hline $\begin{array}{l}\text { Discovering Science } \\
\text { through doing }\end{array}$ & $\begin{array}{l}\text { - "We used rubber bands (on the track) to make the ball (marble) go slower } \\
\text { as there is friction." } \\
\text { - "Yes, yeah (we see Science in our Marble machine). Kinetic energy. } \\
\text { Potential energy, like when you're holding the marble. Then it's kinetic } \\
\text { energy all the way until you drop down to fall." }\end{array}$ \\
\hline $\begin{array}{l}\text { Collaborative } \\
\text { learning with friends }\end{array}$ & $\begin{array}{l}\text { - "Yes, because I get to bond with my friends better by improving their ideas } \\
\text { and it is fun when solving the problem." } \\
\text { "Yes because I could interact and spend time more with my friends. I also } \\
\text { learn a lot of stuff from this activity like in future, if I have activities like } \\
\text { this, I can apply what I've learned." }\end{array}$ \\
\hline $\begin{array}{l}\text { Having fun while } \\
\text { learning }\end{array}$ & $\begin{array}{l}\text { - "Yes, I would consider the activity fun because I got to generate ideas with } \\
\text { my partner and I also got to spend time with her". } \\
\text { - "The activity was fun because while building the machine, we kept laughing } \\
\text { because most of the parts kept on collapsing and we thought it was funny." }\end{array}$ \\
\hline $\begin{array}{l}\text { Learning important } \\
\text { values }\end{array}$ & $\begin{array}{l}\text { - "Teamwork. Me and my partner was having difficulty at first. But when we } \\
\text { - "Ame up with a solution, it was easier." } \\
\text { - "I've learned to become a better person by asking the other groups if any } \\
\text { help is needed when they look like they are in a difficult situation." }\end{array}$ \\
\hline $\begin{array}{l}\text { Thinking like a } \\
\text { Scientist }\end{array}$ & $\begin{array}{l}\text { - "Yeah, I think I was (working like a Scientist) coz in my head I was, when } \\
\text { we were ..that time I took the purple colour, the sheet, then I said that this } \\
\text { can make the marble move faster. Yeah I was thinking like friction and the } \\
\text { surfaces of the marble, what's the difference between the surface of the } \\
\text { marble and the object..." }\end{array}$ \\
\hline
\end{tabular}

As seen from students' comments, Tinkering provided a rich and diverse learning experience where it engages the emotion and cognitive aspects of learning. Thus, we believe that introducing Tinkering activities to NA students could be an effective approach to interest and sustain that interest of Science in them, where learning science concepts through doing, and meeting their affective needs.

\section{Discussion}

Due to the different needs of individuals, organizations, roles and responsibilities of various partners in this complex ecology of partnership, decision-making process is often time-consuming and tedious, even for a simple decision on deciding a workshop date and time that favours all partners. Many times, such decisions also require efforts to align back to research purposes. For instance, in planning a workshop for building the capacities of partners in tinkering approach, instead of adopting the typical 
workshop structure that the Science Centre team has been comfortably doing, the research team suggested a new structure - shorter duration and more targeted to the needs of teachers, as part of the Design-based Implementation Research (DBIR) approach. This suggestion came about after a 3-week period of struggle to confirm a workshop date, that used to be a fast decision made in our first year of the project. The research sensed the shift in needs and goals of teachers but not for the Science Centre team. Since the emerging focus of the 2 nd year of project is about implementation of Tinkering lesson in schools, the research team successfully persuaded Science Centre team to explore a new structure to meet the needs of teachers, despite of a last-minute change. Surprisingly, the outcome of the decision benefitted a school greatly but not the other school. The exact reason is still unclear but confusing moments like this make the research team think harder and wonder, how could we better align the different and shifting needs of the partners as we progress? Such is the complexity of a typical decision the research team needs to make in this multiple agency partnership project. Despite the challenge, one thing for sure is that we have a clear direction and shared goal - to develop the NA students' well-being, promoting their interest in Science and improving their learning outcomes. This shared goal often reminds partners to be open minded, understanding towards each others' perspectives, and be aligned back to the research goals, as the project progresses. This in turn leads us to make collective and mindful decisions through thoughtful negotiation processes. We are realizing the importance of a shared goal as one of the key factors to keeping a healthy partnership growing.

\section{Conclusion}

Preliminary findings showed that such dynamic design processes allow partners to build new relationships and produce new knowledge, enhancing capacities and stretching their abilities in ways that would not have been achieved if not for such a unique partnership. We believe that such partnership holds a promising potential to create a positive impact in lower track students' learning of Science.

\section{References}

Gorski, P. (2008) The myth of the culture of poverty. Educational leadership, 67(7), 32-36.

Kang, T. (2005). Creating educational dreams: The intersection of ethnicity, families and schools. Singapore: Marshall Cavendish.

Kaur, B., \& Ghani, M. (Eds.) (2012). Low attainers in primary Mathematics. Singapore: World Scientific.

Kramer-Dahl, A., \& Kwek, D. (2011). Reading the home and reading in school: Framing deficit constructions as learning difficulties in Singapore English classrooms. In C. Wyatt-Smith et al. (Eds.), Multiple Perspectives on Difficulties in Learning Literacy and Numeracy (pp. 159-178). Singapore: Springer.

Mclnerney, D. M., Liem, A. D., Ortiga, Y. Y., \& Qi, J. (2008). Building the future for Singaporean students: the relationship of values, future vision, motivational profiles, and learning to school success. Final Research Report. Singapore: National Institute of Education, Centre for Research in Pedagogy and Practice.

Resnick, M., \& Rosenbaum, E. (2013). Designing for tinkerability. Design, make, play: Growing the next generation of STEM innovators, 163-181.

Tan, O. S., Wang, C. K., Ee, J., Koh, C., \& Liu, W. C. (2009). Enhancing learning for Normal stream students: Insights into cognitive and motivational processes in project work. Final research report. Singapore: National Institute of Education, Office of Education Research.

Teo, T. W., Goh, J. W. P., Aye, K. M., \& Yeo, L. W. (2018). Rethinking teaching and learning of science inference competencies of lower track students in Singapore: a Rasch investigation. Asia Pacific Journal of Education, 38(3), 279-302.

Wang, L. Y., Teng, S. S., \& Tan, C. S. (2014). Levelling up academically low progress students (NIE Working Paper Series No. 3). Singapore: National Institute of Education. 